\title{
5-Aminolevulinic acid enhances mitochondrial stress upon ionizing irradiation exposure and increases delayed production of reactive oxygen species and cell death in glioma cells
}

\author{
KUNIHIRO UETA $^{1}$, JUNKOH YAMAMOTO ${ }^{1}$, TOHRU TANAKA ${ }^{2}$, YOSHITERU NAKANO ${ }^{1}$, \\ TAKEHIRO KITAGAWA ${ }^{1}$ and SHIGERU NISHIZAWA ${ }^{1}$ \\ ${ }^{1}$ Department of Neurosurgery, University of Occupational and Environmental Health, \\ Kitakyushu, Fukuoka; ${ }^{2}$ SBI Pharmaceuticals Co., Ltd., Minato-ku, Tokyo, Japan
}

Received May 23, 2016; Accepted December 6, 2016

DOI: $10.3892 /$ ijmm.2016.2841

\begin{abstract}
Aminolevulinic acid (5-ALA) can accumulate protoporphyrin IX (PpIX) in tumour cell mitochondria and is well known for its utility in fluorescence-guided resection of malignant gliomas as a live molecular marker. Previously, we and other authors demonstrated that 5-ALA has a radiosensitizing effect for tumours. In the present study, we aimed to investigate the mechanism underlying the radiosensitizing effect of 5-ALA by focusing on glioma cell mitochondria. Using an enhancer (ciprofloxacin) of 5-ALA-induced PpIX accumulation, we evaluated the influence of ionizing irradiation (IR) and delayed reactive oxygen species (ROS) production $12 \mathrm{~h}$ after IR by colony-forming assay and flow cytometry (FCM) with different amounts of PpIX accumulation. The mitochondrial mass and mitochondrial electron transport chain (mtETC) activity were evaluated by FCM and western blot analysis. Cell death and delayed ROS production after IR in glioma cells were increased in proportion to 5-ALA-induced PpIX accumulation. Delayed ROS production enhanced by 5-ALA localized to the glioma cell mitochondria. Mitochondrial mass and mitochondrial complex III activity, among mtETC factors, were also increased $12 \mathrm{~h}$ after IR in glioma cells in proportion to 5-ALA-induced PpIX accumulation with some variation. These results suggest that 5-ALA enhances IR-induced mitochondrial oxidative stress and leads to increased cell death with mitochondrial changes, thereby acting as a targeting mitochondrial drug, and so-called radiosensitizer in glioma cells.
\end{abstract}

\section{Introduction}

Glioblastoma (GBM) is the most common primary brain tumour in adults and is usually lethal. Standard treatment for

Correspondence to: Dr Junkoh Yamamoto, Department of Neurosurgery, University of Occupational and Environmental Health, 1-1 Iseigaoka, Yahatanishi-ku, Kitakyushu, Fukuoka 807-8555, Japan E-mail: yama9218@med.uoeh-u.ac.jp

Key words: 5-aminolevulinic acid, mitochondrion, radiotherapy, glioblastoma, cancer, ciprofloxacin, radiosensitizer, free radical
GBM includes tumour resection [from $78 \%$ to nearly $100 \%$ of the contrast-enhanced tumour volume in magnetic resonance imaging (MRI)] followed by concomitant chemotherapy, particularly with temozolomide, and radiation therapy $(1,2)$. However, despite these multimodal treatments, the mean survival time for patients with GBM is $12-14$ months $(2,3)$. Because of its aggressive infiltrative behaviour, most GBMs rapidly invade neighbouring brain structures and have a high recurrence rate (4). Up to $85 \%$ of recurrences are within the previous radiation treatment field (5).

5-Aminolevulinic acid (5-ALA) is a natural biochemical precursor of heme that is converted by the heme synthesis pathway into protoporphyrin IX (PpIX), a photosensitizing porphyrin. Following systemic administration, 5-ALA metabolism leads to the relative accumulation of PpIX in tumour cell mitochondria $(6,7)$. In particular, 5-ALA induces a high accumulation of PpIX in glioma cells; thus, florescence-guided resection using 5-ALA in high-grade glioma treatment has been useful in determining tumour borders, facilitating tumour resection compared to conventional microsurgery (8-10). Although several porphyrin compounds, including hematoporphyrin derivatives (HpD) and Photofrin, can act as radiosensitizers, the radiosensitizing activity of 5-ALA remains controversial (11-13). We previously demonstrated the radiosensitizing effects of 5-ALA in experimental gliomas in vitro and in vivo (14-16). Other studies similarly reported that radiotherapy combined with 5-ALA strongly inhibits tumour growth in mouse melanoma, colon cancer, and prostate cancer models (17-19). A recent DNA microarray study further demonstrated that 5-ALA enhanced gene expression induced by ionizing irradiation (IR) in cancer cells, such as those involved in cell cycle arrest (20).

The mechanism underlying the radiosensitizing effect of 5-ALA remains unclear. In general, IR causes the ionization and excitation of water, leading to reactive oxygen species (ROS) production (particularly hydroxyl radical). Primary ROS induce double-strand breaks (DSB) in nuclear DNA and reproductive cell death $(21,22)$. A previous study reported that production of ROS, such as superoxide, singlet oxygen, and hydroxyl radical, was increased in PpIX solutions under IR exposure (23). Consistently, we confirmed that the production of primary ROS was increased, and the 
subcellular localization of primary ROS coincided with 5-ALA-induced PpIX in glioma cells after 5-ALA treatment under IR exposure (14). Thus, 5-ALA-induced PpIX may be a key mediator and enhance the production of primary ROS under IR exposure, thereby increasing reproductive cell death in tumours. Otherwise, this initial reaction during exposure to IR occurs only for a short period of time (21). Furthermore, we observed strong inhibition of in vivo tumour growth under IR exposure with 5-ALA administration (15). Tumour specimens at 16 days after IR with 5-ALA administration exhibited strong aggregation of cytotoxic Iba-1-positive macrophages with phagocytosis (15). Even after considering the immunological effects, whether tumour growth in glioma is strongly inhibited by short-term ROS-induced DSB in nuclear DNA and subsequent reproductive cell death alone remains to be determined.

Recent findings demonstrated that IR increases mitochondrial membrane potential, respiration, and ATP production and causes ROS production in the mitochondria of tumour cells (24-26). These ROS (particularly superoxide and hydrogen peroxide) are secondary species produced by primary ROS (particularly hydroxyl radical) via water radiolysis $(25,27)$. Importantly, this secondary process occurs in mitochondria of tumour cells and induces long-lasting ROS production $>24 \mathrm{~h}$ after IR exposure $(24,28)$. During these processes, impaired mitochondria that were damaged by oxidative stress from primary ROS cause several changes, such as synthesis of new mitochondria (increased mitochondrial mass), synthesis of new mitochondrial DNA (mitochondrial polyploidization), and instability of the mitochondrial electron transport chain (ETC) complex, to cope with their own oxidative damage. However, these impaired mitochondria also produce large amounts of secondary ROS and propagate oxidative damage to the surrounding normal mitochondria and nucleus. This intermitochondrial communication amplifies the damage signal and production of secondary ROS, permanently damages the remaining normal mitochondria and nuclear DNA, and eventually leads to cell death (25). Previously, we demonstrated that the delayed intracellular production of ROS $12 \mathrm{~h}$ after IR exposure was enhanced in glioma cells after 5-ALA treatment, particularly in the cytoplasm (16). In addition, 5-ALA treatment can cause marked accumulation of PpIX in glioma cell mitochondria and improve mitochondrial dysfunction by improving cytochrome $c$ oxidase activity to restore oxidative phosphorylation, thereby disrupting the Warburg effect in tumour cells (29). Thus, we hypothesized that 5-ALA, by inducing PpIX accumulation within tumour cell mitochondria, may cause mitochondrial changes following IR exposure, such as increased mitochondrial mass and altered activity of the ETC complex in gliomas, leading to cell death.

In the present study, we assessed the radiosensitizing effect of 5-ALA using ciprofloxacin (CPFX), which is a known enhancer of 5-ALA-induced PpIX accumulation (31), in glioma cells. We evaluated the subcellular localization of secondary ROS and mitochondria by confocal laser scanning microscopy and the delayed changes in mitochondrial mass and ETC complex activity after IR exposure with different amounts of 5-ALA-induced PpIX in glioma cells. Finally, we considered the possible mechanisms underlying the radiosensitizing effect of 5-ALA based on the effects observed for mitochondria.

\section{Materials and methods}

Chemicals. 5-ALA was provided by SBI Pharmaceuticals Co., Ltd. (Tokyo, Japan) and dissolved in fresh culture medium at a final concentration of $1 \mathrm{mM}$ for intracellular ROS imaging and $0.3 \mathrm{mM}$ for other in vitro experiments. CPFX was purchased from WAKO Pure Chemical Co. (Osaka, Japan). CM-H2DCFDA (DCFD), MitoTracker Green FM, and Mito Tracker Deep Red FM were purchased from Sigma-Aldrich K.K. (Tokyo, Japan) and Invitrogen (Carlsbad, CA, USA). DCFD was dissolved in Hank's Balanced Salt Solution (HBSS) with calcium and magnesium and without red phenol 1X (Invitrogen) at a final concentration of $10 \mu \mathrm{M}$. MitoTracker Green FM and MitoTracker Deep Red FM were dissolved in fresh culture medium at a final concentration of $50 \mathrm{nM}$. Other materials were of the highest grade available.

Culture and treatment of cells. A rat glioma cell line (9L) and a human glioma cell line (U251) were used (16). The 9L cells were cultured for several days in RPMI-1640, and U251 cells were cultured in Dulbecco's modified Eagle's medium (DMEM) with $10 \%$ fetal bovine serum (FBS) at $37^{\circ} \mathrm{C}$ before use. These cell lines were maintained in a humidified incubator with 5\% $\mathrm{CO}_{2}$ at $37^{\circ} \mathrm{C}$. Cells were passaged in the exponential growth phase using a $0.05 \%$ trypsin solution containing $0.5 \mathrm{mM}$ ethylenediaminetetraacetic acid. Cells at 70\% confluency were used in the subsequent experiments. 5-ALA was dissolved in RPMI-1640 (9L) or DMEM (U251) with 10\% FBS to achieve a final concentration of 0.3 or $1 \mathrm{mM}$ and incubated with $9 \mathrm{~L}$ or U251 cells for $4 \mathrm{~h}$. These 5-ALA concentrations and incubation time were used in the subsequent experiments. CPFX was dissolved in water and then diluted to the appropriate concentration in RPMI-1640 (9L) or DMEM (U251) with 10\% FBS and incubated with 9L or U251 cells for $24 \mathrm{~h}$. For cotreatment with CPFX and 5-ALA, the cells were initially incubated with CPFX medium for $24 \mathrm{~h}$, washed with phosphate-buffered saline (PBS), and immediately incubated in complete medium containing $0.3 \mathrm{mM} 5$-ALA for $4 \mathrm{~h}(30,31)$.

MTT assay. Cells were seeded in 96-well plates at a density of $5 \times 10^{3}$ cells/well and incubated in medium containing various concentration of CPFX for $24 \mathrm{~h}(30,31)$. The MTT assay was conducted using a Cell Titer 96R Non-Radioactive Cell Proliferation assay (Promega K.K., Tokyo, Japan). After exposure to CPFX, the cells were washed with PBS, and MTT solution was added. The cells were incubated with MTT solution for $4 \mathrm{~h}$, the reaction was terminated with Stop solution, and the cells were incubated another $4 \mathrm{~h}$. The absorbance of the coloured solutions was measured at 550/655 nm on Microplate Manager software (version 5.2.1; Bio-Rad Laboratories, Hercules, CA, USA). The results for cell viability are presented relative to control cells.

Flow cytometric analyses. After each period of incubation, the cells were detached from the substratum by trypsinization and collected by centrifugation $\left(400 \mathrm{xg}\right.$ for $3 \mathrm{~min}$ at $\left.4^{\circ} \mathrm{C}\right)$. Immediately afterwards, the cells were resuspended in cold PBS/FBS and analysed using a flow cytometer (EC800; Sony Biotechnology, Tokyo, Japan). Overall, $3 \times 10^{6}$ cells in each sample were evaluated. Analyses of flow cytometric data were 
carried out using FlowJo (Tree Star Inc., Ashland, OR, USA). The median fluorescence intensity (MFI) of various parameters in treated glioma cells relative to that of the control cells was calculated for each cell line as we described previously (16).

Evaluation of PpIX fluorescence intensity in glioma cells. Cells were seeded in $100-\mathrm{mm}$ culture dishes and cultured in complete medium containing $0.3 \mathrm{mM}$ 5-ALA for $4 \mathrm{~h}$ (5-ALA group) or CPFX for $24 \mathrm{~h}$ (CPFX group) and then washed with PBS. The cells in the 5-ALA with CPFX group were incubated with $5 \mu \mathrm{M}$ CPFX for $24 \mathrm{~h}$, washed with PBS, and immediately incubated in complete medium containing $0.3 \mathrm{mM} 5$-ALA for $4 \mathrm{~h}(30,31)$. After culture, we immediately assessed PpIX fluorescence using a flow cytometer (excitation, $488 \mathrm{~nm}$; emission, 640/30 nm band-pass filter). Control cells were not exposed to 5-ALA or CPFX. Analyses of flow cytometric data were carried out using FlowJo. The MFI of PpIX for treated cells relative to that of the control cells was calculated for each cell line.

Evaluation of cell responses to IR. Cells were seeded at a density of 100 cells $(0 \mathrm{~Gy})$ or 400 cells $(8 \mathrm{~Gy})$ for $9 \mathrm{~L}$ and 400 cells $(0 \mathrm{~Gy})$ or 4,000 cells $(8 \mathrm{~Gy})$ for $\mathrm{U} 251$ per $60-\mathrm{mm}$ culture dish based on preliminary measurements to determine the optimal cell concentration for each irradiation dose. The cells in each group were treated as described above and then washed with PBS $(30,31)$. Cells exposed only to IR without 5-ALA or CPFX were prepared for comparison. The culture dishes were stored in a light-protected humidified chamber to avoid activation of 5-ALA-induced PpIX. After the medium was replaced with $3 \mathrm{ml}$ fresh culture medium, the cells were irradiated using a Gamma-irradiator (Gammacell 40 Extractor; Nordion International, Inc., Kanata, ON, Canada) at $8 \mathrm{~Gy}(0.71 \mathrm{~Gy} / \mathrm{min})$. During IR, the culture dishes were kept in a dark container at room temperature. The response of the cells to IR was evaluated using a standard colony-forming assay (14). Briefly, after 12 days of irradiation treatment, the cells were fixed and stained using a Diff Quick Staining kit (Sysmex Co., Kobe, Japan). Two culture dishes were prepared for each dose point, and three independent experiments were performed. Only colonies containing $\geq 50$ cells were scored. Plating efficiency was determined for unirradiated controls treated in the same manner and maintained under the same conditions. The surviving fraction was then calculated and presented relative to control cells without 5-ALA or CPFX treatment and IR exposure.

Detection of subcellular localization of ROS and mitochondria $12 \mathrm{~h}$ after IR in $9 \mathrm{~L}$ cells. Intracellular production of ROS was detected using the oxidant-sensitive fluorescent probe DCFD, and mitochondria were detected using Mito Tracker Deep Red FM with a confocal laser-scanning microscope (LMS5 Pascal; Carl Zeiss, Jena, Germany) (16). Cells were seeded in 35-mm glass-bottom dishes (Asahi Techno Glass, Tokyo, Japan). After each period of incubation with $1 \mathrm{mM}$ 5-ALA, cells were washed with PBS and exposed to 10 Gy IR. At $12 \mathrm{~h}$ after IR, the cells were washed twice with PBS, incubated with 50 nM Mito Tracker Deep Red FM for 30 min, washed again with PBS, and immediately incubated with $10 \mu \mathrm{M}$ DCFD for 15 min. After washing twice with PBS, the cells were observed immediately. Mito Tracker Deep Red fluorescence (excitation, 488/633 nm; emission, $650 \mathrm{~nm}$ band-pass filter) and DCFD fluorescence (excitation, 488/633 nm; emission, 505-530-nm band-pass filter) were imaged on a confocal laser-scanning microscope. In addition, control cells without 5-ALA treatment and with or without IR were prepared for comparison. All procedures were carried out in the dark.

Evaluation of intracellular ROS levels after IR in glioma cells. Intracellular production of ROS $12 \mathrm{~h}$ after IR was assessed using DCFD, an oxidant-sensitive fluorescent probe, using a flow cytometer (16). Cells in the 5-ALA group, the CPFX group, and the 5-ALA with CPFX group were seeded in 100-mm culture dishes and prepared as described above. Immediately thereafter, the cells were irradiated with $8 \mathrm{~Gy} \gamma$-irradiation at room temperature in the dark using a $\gamma$-irradiator. At $12 \mathrm{~h}$ after exposure to IR, the cells were incubated with $10 \mu \mathrm{M}$ DCFD for $15 \mathrm{~min}$ at $37^{\circ} \mathrm{C}$ and washed twice with PBS. DCFD fluorescence was then analysed using a flow cytometer (excitation, $488 \mathrm{~nm}$; emission, 525/50 nm band-pass filter) as described above. Control cells did not receive 5-ALA and CPFX treatment or IR exposure. Cells exposed to IR without 5-ALA or CPFX treatment were also prepared for comparison. Analyses of flow cytometric data were carried out using FlowJo. The MFI of DCFD for treated cells relative to that of control cells was calculated for each cell line.

Evaluation of mitochondrial mass after IR in glioma cells. Mitochondrial mass was measured by staining cells with MitoTracker Green FM (24). The cells were seeded in 100-mm culture dishes as described above and then irradiated with $8 \mathrm{~Gy}$ $\gamma$-irradiation at room temperature in the dark. Immediately and at $12 \mathrm{~h}$ after IR, the cells were incubated with $50 \mathrm{nM}$ Mito Tracker Green FM for $30 \mathrm{~min}$ at $37^{\circ} \mathrm{C}$ and then washed twice with PBS. Mito Tracker Green FM fluorescence was analysed using a flow cytometer (excitation, $488 \mathrm{~nm}$; emission, $525 / 50 \mathrm{~nm}$ band-pass filter). Control cells were not exposed to IR or 5-ALA and CPFX. Analyses of flow cytometric data were carried out using FlowJo. The MFI of Mito Tracker Green FM for treated cells relative to that of the control cells was calculated for each cell line.

Evaluation of mitochondrial ETC activity after IR by western blot analysis. Mitochondrial ETC activity was evaluated by western blotting using Total OXPHOS Rodent WB Antibody Cocktail $(32,33)$. Cells were seeded in 100-mm culture dishes and treated as described above. Thereafter, the cells were irradiated with $8 \mathrm{~Gy}$ in the dark using a $\gamma$-irradiator. Before, immediately after, and $12 \mathrm{~h}$ after IR, the cells were washed with PBS and lysed in $0.4 \mathrm{ml}$ lysis buffer [RIPA buffer:Halt protease inhibitor cocktail (1:100; Thermo Fisher Scientific, Rockford, IL, USA)]. Protein $(20 \mu \mathrm{g})$ was separated by polyacrylamide gel electrophoresis (4-15\%) and transferred to PVDF membranes (Bio-Rad Laboratories). The membranes were blocked for $1 \mathrm{~h}$ with $1 \%$ bovine serum albumin (Sigma-Aldrich) in Tris-buffered saline, $\mathrm{pH}$ 7.6, containing $0.1 \%$ Tween-20 (T-TBS) and washed once with T-TBS. The membranes were incubated for $1 \mathrm{~h}$ with 1:800 Total OXPHOS Rodent WB Antibody Cocktail (ab110413) or 1:1,000 rabbit anti- $\beta$-actin polyclonal antibody (ab8227) (both from Abcam) 
at room temperature, washed three times for $10 \mathrm{~min}$ in T-TBS, and incubated for $1 \mathrm{~h}$ with 1:50,000 HRP-linked sheep anti-mouse IG (NA931) or 1:50,000 HRP-linked donkey antirabbit IG (NA934) (both from GE Healthcare, Logan, UT, USA) at room temperature. The blots were visualized using ImmunoStar ${ }^{\circledR}$ LD (Wako, Tokyo, Japan) with a C-DiGit ${ }^{\mathrm{TM}}$ Blot Scanner (LI-COR, Lincoln, NE, USA), quantitatively analysed using the public domain software ImageJ 1.46r (National Institutes of Health, Bethesda, MD, USA), and normalized to actin for each experiment. The ratio of blots was compared to that of control bands. Control blots were not exposed to IR, 5-ALA or CPFX.

Statistical analyses. Data are presented as means \pm SE and were analysed with Fisher's protected least significant difference test. $\mathrm{P}<0.05$ was considered statistically significant.

\section{Results}

Cytotoxic influence of CPFX on viability of glioma cell lines. First, we evaluated an appropriate concentration of CPFX for 9L and U251 cells using an MTT assay at 5, 15, 25, 50, 100, 200 and $500 \mu \mathrm{M}$ CPFX. Cytotoxicity was not observed at $5 \mu \mathrm{M}$ CPFX for 9L and U251 cells $(\mathrm{p}=0.2881$ and 0.6386 , respectively). However, at $15 \mu \mathrm{M}$ CPFX, the survival rate of cells significantly decreased compared to controls in the two cell lines ( $p=0.0255$ in 9L, and $p=0.0162$ in U251) (Fig. 1A and B). To avoid CPFX cytotoxicity for glioma cells, we therefore used $5 \mu \mathrm{M}$ CPFX for all subsequent experiments.

Low-dose CPFX enhances 5-ALA-induced PpIX accumulation and leads to increased cell death after IR in glioma cells. We examined the influence of low-dose CPFX on the intracellular accumulation of 5-ALA-induced PpIX in glioma cells using flow cytometric analyses. The MFI of PpIX in 5-ALA-treated cells was obviously increased compared with the control cells in the two cell lines, consistent with our previous results (Fig. 1C and D) (16). In addition, the MFI of PpIX in cells treated with 5-ALA and low-dose CPFX was significantly increased compared with that for cells treated only with 5-ALA for the two cell lines (Fig. 1C and D). The relative MFI of PpIX (mean \pm SE) in 9L cells was 7.28 \pm 0.05 and $7.89 \pm 0.06$ in the 5-ALA group and the 5-ALA with CPFX group, respectively $(\mathrm{p}<0.0001)$. Similarly, the relative MFI of PpIX (mean \pm SE) in U251 cells was $16.0 \pm 0.13$ and $17.6 \pm 0.20$ in the 5-ALA group and the 5-ALA with CPFX group, respectively $(\mathrm{p}<0.0001)$. By contrast, the relative MFI of PpIX (mean \pm SE) in 9L and U251 cells was $1.03 \pm 0.01$ and $1.03 \pm 0.01$, respectively, in the CPFX group, and there were no significant differences compared to controls for either cell line $(\mathrm{p}=0.4852$ and 0.8427 , respectively).

Next, we tested the influence of IR under the production of 5-ALA-induced PpIX enhanced by low-dose CPFX treatment in 9L and U251 cells. In 9L cells, the surviving fraction (\%) in the RT group, RT with 5-ALA treatment group, and RT with 5-ALA and CPFX treatment group was $8.38 \pm 0.70,6.38 \pm 0.33$, and $4.57 \pm 0.37$, respectively (Fig. $2 \mathrm{~A}$ ). The surviving fraction in the RT with 5-ALA treatment group was significantly lower than that in the RT group $(\mathrm{p}=0.0118)$. Moreover, RT with 5-ALA and CPFX treatment significantly decreased the surviving fraction compared to that for RT with 5-ALA treatment $(\mathrm{p}=0.0188)$ (Fig. 2A). In U251 cells, the surviving fraction (\%) in the RT group, the RT with 5-ALA treatment group, and the RT with 5-ALA and CPFX treatment group was $18.50 \pm 1.05,14.7 \pm 1.16$ and $11.7 \pm 0.62$, respectively (Fig. 2B). The surviving fraction in the RT with 5-ALA treatment group was significantly lower than that in the RT group $(p=0.0162)$. Similar to the results with 9L cells, RT with 5-ALA and CPFX treatment significantly decreased the surviving fraction compared to that for RT with 5-ALA treatment $(\mathrm{p}=0.0480)$ in U251 cells (Fig. 2B). The surviving fraction in the RT with CPFX treatment group $(6.65 \pm 0.15)$ was significantly decreased compared to that in the RT group in 9L cells $(p=0.0234)$, but there was no significant difference between RT with CPFX (16.95 \pm 0.58$)$ and only RT in U251 cells $(\mathrm{p}=0.2567)$.

Differences in the amount of 5-ALA-induced PpIX accumulation influence delayed production of intracellular ROS after IR in glioma cells. To evaluate the influence of different amounts of 5-ALA-induced PpIX accumulation on the delayed production of intracellular ROS after IR, we evaluated ROS production $12 \mathrm{~h}$ after IR in glioma cells treated with low-dose CPFX using flow cytometric analysis. In 9L cells, the relative MFI of DCFD in the RT, RT with CPFX treatment, RT with 5-ALA treatment, and RT with 5-ALA and CPFX treatment groups was $1.40 \pm 0.04,1.72 \pm 0.02,1.522 \pm 0.39$ and $1.62 \pm 0.04$, respectively (Fig. 3A). Although delayed ROS production with RT only significantly increased compared to the control $(\mathrm{p}<0.0001)$, that in the RT with 5-ALA treatment group also significantly increased compared to that in the RT group $(\mathrm{p}=0.0110)$, consistent with our previous results (16). Moreover, delayed ROS production in the RT with 5-ALA and CPFX treatment group significantly increased compared to that in the RT with 5-ALA treatment group ( $\mathrm{p}=0.0382)$. In the U251 cells, the relative MFI of DCFD in the RT, RT with CPFX treatment, RT with 5-ALA treatment, and RT with 5-ALA and CPFX treatment groups was $1.23 \pm 0.02,1.56 \pm 0.06,1.45 \pm 0.09$ and $1.72 \pm 0.13$, respectively (Fig. 3B). Similar to the effects in $9 \mathrm{~L}$ cells, although delayed ROS production with RT only significantly increased compared to control $(\mathrm{p}=0.0477)$, that in the RT with 5-ALA treatment group also significantly increased compared to that in the RT group ( $\mathrm{p}=0.0495)$ in the U251 cells, consistent with our previous results (16). Additionally, delayed ROS production in the RT with 5-ALA and CPFX treatment group also significantly increased compared to that in the RT with 5-ALA treatment group ( $\mathrm{p}=0.0199)$. By contrast, delayed ROS production for RT with CPFX treatment significantly increased compared to that for RT alone in the two cell lines $(\mathrm{p}<0.001$ in $9 \mathrm{~L}, \mathrm{p}=0.0048$ in U251).

Subcellular localization of delayed intracellular ROS production and mitochondria after IR in glioma cells. In a previous study, we detected delayed intracellular ROS production enhanced by IR with 5-ALA treatment mainly in the cytoplasm of glioma cells (16). To determine the more precise localization of delayed ROS production, we observed delayed ROS production in 9L cells $12 \mathrm{~h}$ after IR using the oxidant-sensitive probe DCFD and mitochondrial staining (MitoTracker Deep Red FM) by confocal laser-scanning microscopy (Fig. 4). In preliminary experiments, we confirmed no PpIX fluorescence 
A
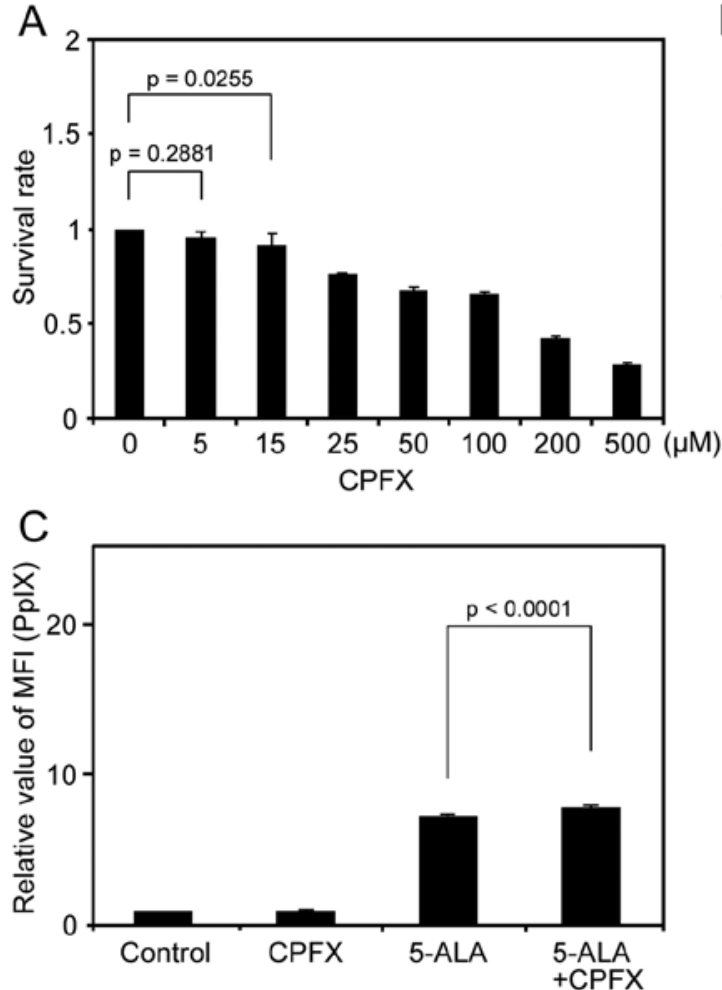

B
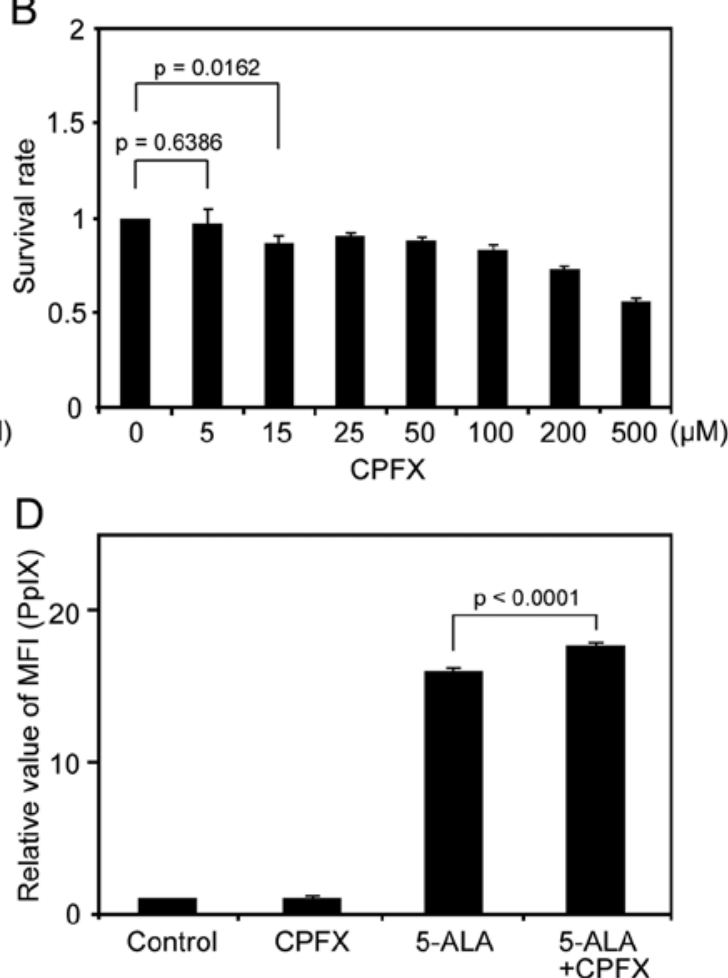

Figure 1. Cell viability in glioma cells after treatment with ciprofloxacin (CPFX) (A and B). Glioma cells were treated with various concentrations of CPFX and incubated for $24 \mathrm{~h}$. Intracellular protoporphyrin IX (PpIX) fluorescence in glioma cells using flow cytometric analyses (C and D). Glioma cells were treated as follows: CPFX, cells treated with only $5 \mu \mathrm{M}$ CPFX; 5-aminolevulinic acid (5-ALA), cells treated with only $0.3 \mathrm{mM} 5$-ALA; 5-ALA+CPFX, cells treated with $0.3 \mathrm{mM} 5$-ALA and $5 \mu \mathrm{M}$ CPFX. Control cells were treated without 5-ALA or CPFX. Relative median fluorescence intensity (MFI) of PpIX compared with the control in the glioma cells. (A and C) 9L cells. (B and D) U251 cells. Values indicate mean $\pm \mathrm{SE}(\mathrm{n}=4)$.
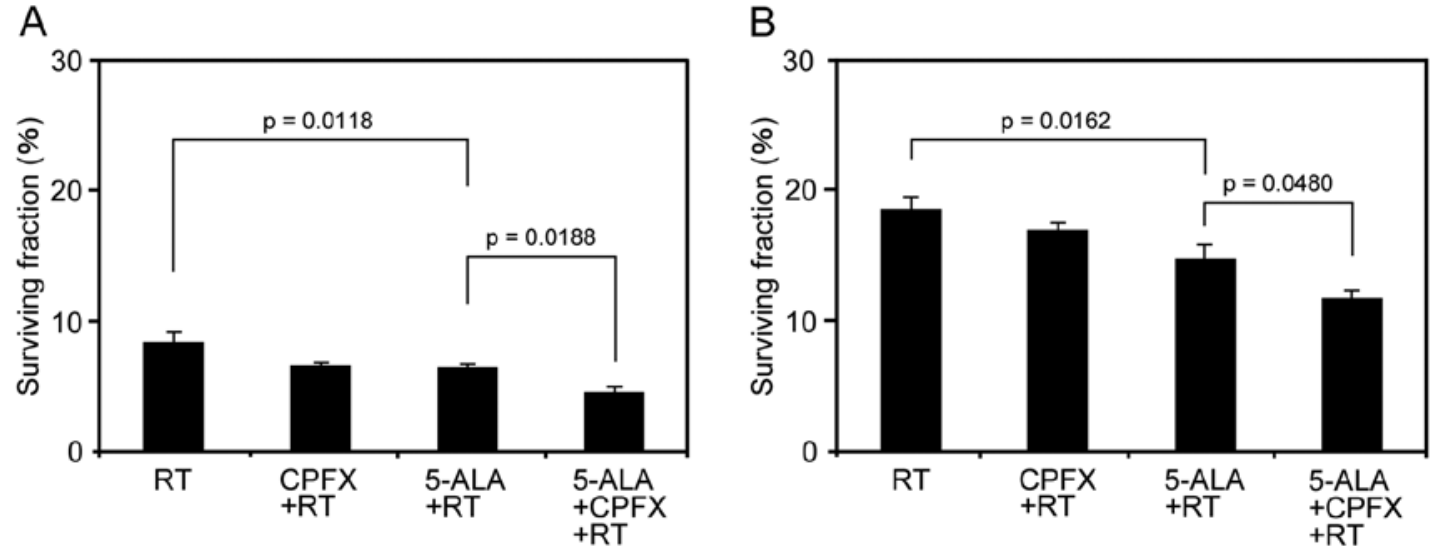

Figure 2. Surviving fraction after ionizing irradiation exposure in glioma cells. (A) $9 \mathrm{~L}$ cells. (B) U251 cells. Cells were treated with $5 \mu \mathrm{M}$ ciprofloxacin (CPFX) and/or $0.3 \mathrm{mM} \mathrm{5-aminolevulinic} \mathrm{acid} \mathrm{(5-ALA)} \mathrm{and} \mathrm{then} \mathrm{exposed} \mathrm{to} \mathrm{single-dose} \mathrm{ionizing} \mathrm{irradiation} \mathrm{at} 8 \mathrm{~Gy}$. The surviving fraction was evaluated using a standard colony-forming assay. RT, cells exposed to only ionizing irradiation without CPFX and 5-ALA; CPFX+RT, cells pretreated with CPFX and exposed to ionizing irradiation; 5-ALA+RT, cells pretreated with 5-ALA and exposed to ionizing irradiation; 5-ALA+CPFX+RT; cells pretreated with CPFX and 5 -ALA and exposed to ionizing irradiation. Values indicate mean $\pm \mathrm{SE}(\mathrm{n}=3)$.

in $9 \mathrm{~L}$ cells $12 \mathrm{~h}$ after 5-ALA treatment under our imaging conditions. Mitochondrial fluorescence was clearly observed in 9L cells without 5-ALA treatment and IR exposure as a control (Fig. 4A, D and J). In addition, no interaction between mitochondria and DCFD fluorescence was observed following our imaging study (Fig. 4D and G). Mitochondrial fluorescence in 9L cells $12 \mathrm{~h}$ after RT was increased compared to that in the control (Fig. 4D and E). Moreover, mitochondrial fluorescence in 9L cells $12 \mathrm{~h}$ after RT with 5-ALA treatment obviously increased compared to other groups (Fig. 4F). In addition, slight DCFD fluorescence in 9L cells $12 \mathrm{~h}$ after RT was observed in the nucleus and cytoplasm (Fig. 4H). DCFD fluorescence in 9L cells $12 \mathrm{~h}$ after RT with 5-ALA treatment obviously increased compared to other groups and was localized mainly in the cytoplasm, consistent with our previous results (16) (Fig. 4I). Furthermore, the enhanced DCFD fluorescence in RT with 5-ALA treatment coincided with mitochondrial fluorescence (Fig. 4L). 

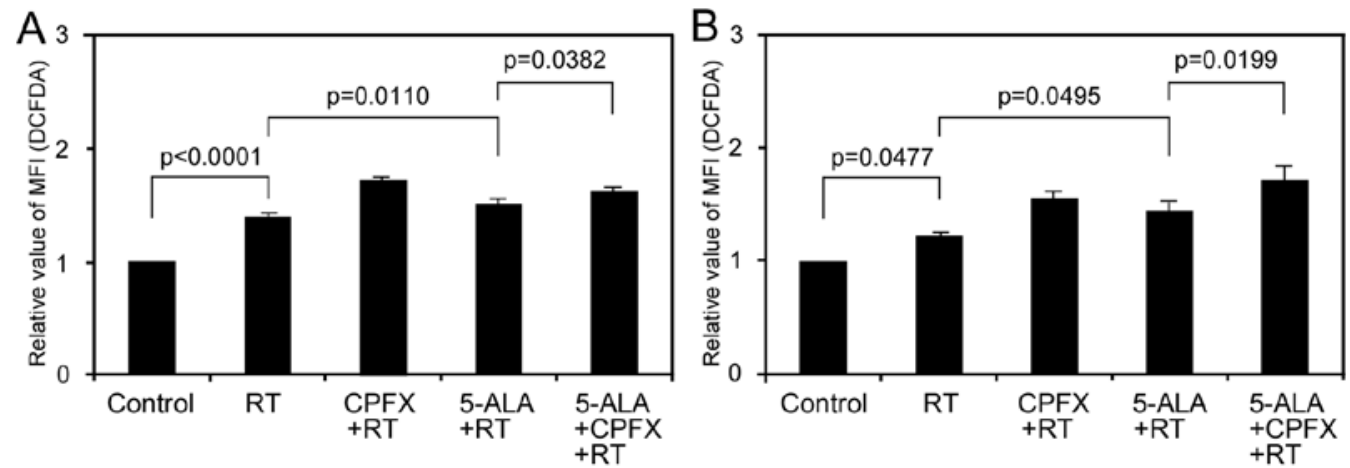

Figure 3. Intracellular production of reactive oxygen species (ROS) $12 \mathrm{~h}$ after ionizing irradiation exposure in glioma cells using flow cytometric analyses. ROS were detected with an oxidant-sensitive fluorescent probe (DCFD). Control cells did not receive 5-aminolevulinic acid (5-ALA) or ciprofloxacin (CPFX) treatment and were not exposed to ionizing irradiation. Relative median fluorescence intensity (MFI) of intracellular ROS levels $12 \mathrm{~h}$ after ionizing irradiation with 5-ALA and/or CPFX pretreatment compared with the control in 9L cells (A) and U251 cells (B). Values indicate mean \pm SE ( $n=6)$.
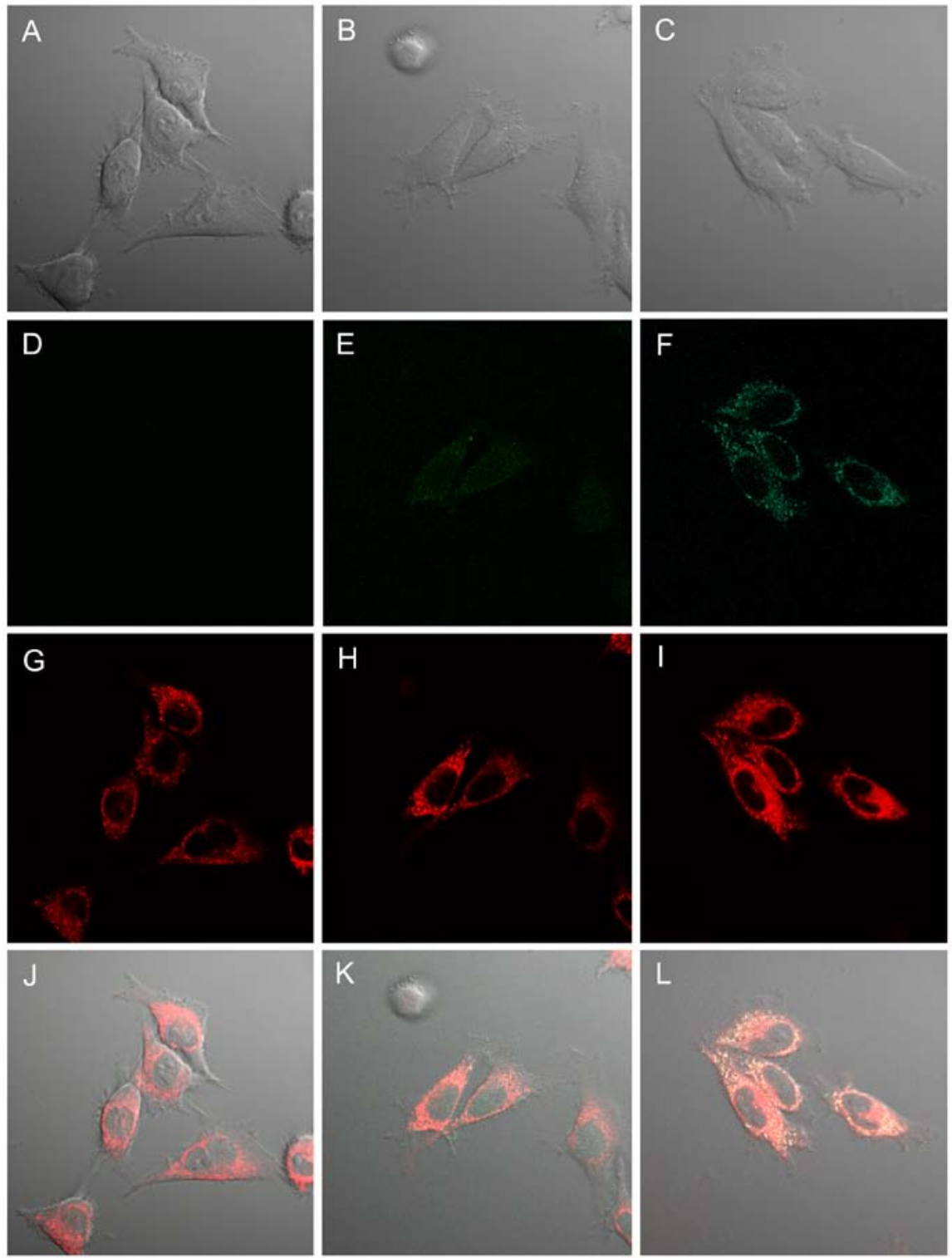

Figure 4. Visualization of intracellular reactive oxygen species (ROS) and mitochondria after ionizing irradiation exposure in 9L cells. Control cells did not received 5-aminolevulinic acid (5-ALA) treatment or ionizing irradiation (A, D, G and J). Cells were exposed to ionizing irradiation (10 Gy) without 5-ALA treatment for comparison (B, E, H and K). Cells were treated with $1 \mathrm{mM}$ 5-ALA and then exposed to ionizing irradiation (10 Gy) (C, F, I and L). Twelve hours after ionizing irradiation, the cells were treated with $50 \mathrm{nM}$ Mito Tracker Deep Red FM to identify mitochondria and $10 \mu \mathrm{M}$ DCFD to identify intracellular ROS. (A-C) Bright-field image. (D-F) Mito Tracker Deep Red FM fluorescence image. (G-I) DCFD fluorescence image. (J-L) Merged image of Mito Tracker Deep Red FM fluorescence, DCFD fluorescence, and bright-field images. No interaction in fluorescence between Mito Tracker and DCFD was observed in our imaging conditions (D and $\mathrm{G})$. 

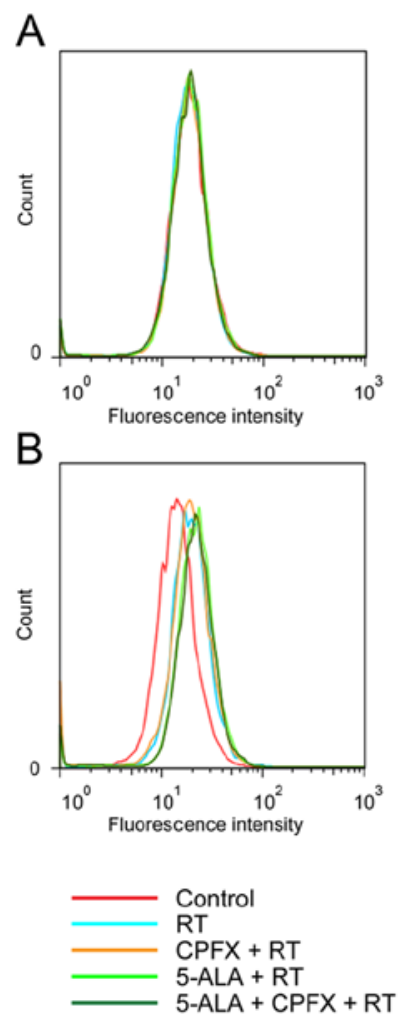

C
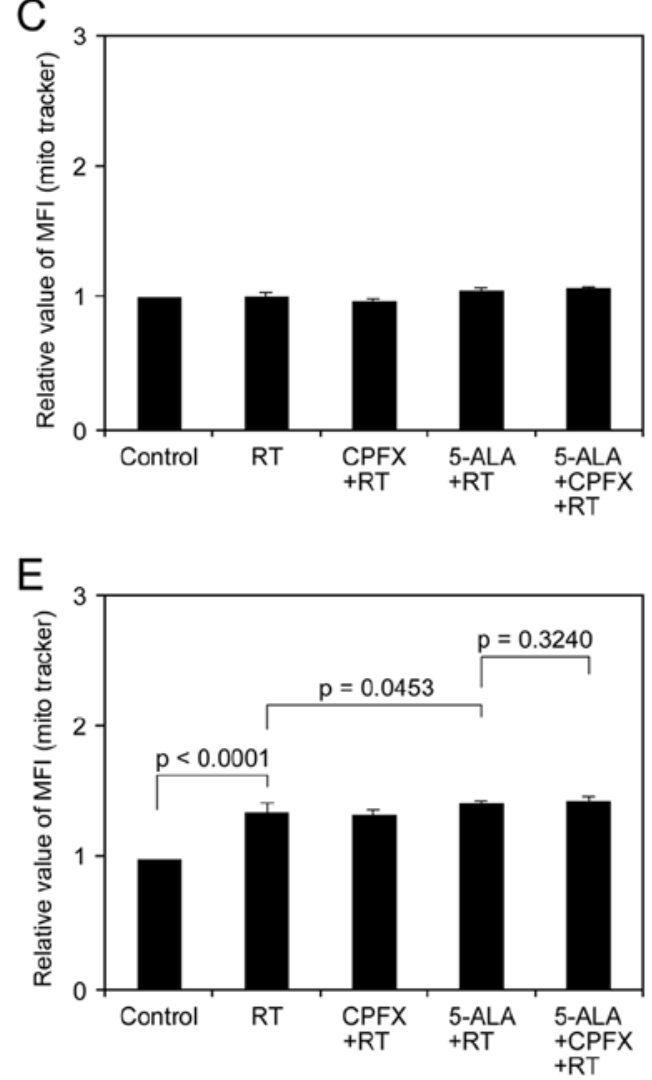

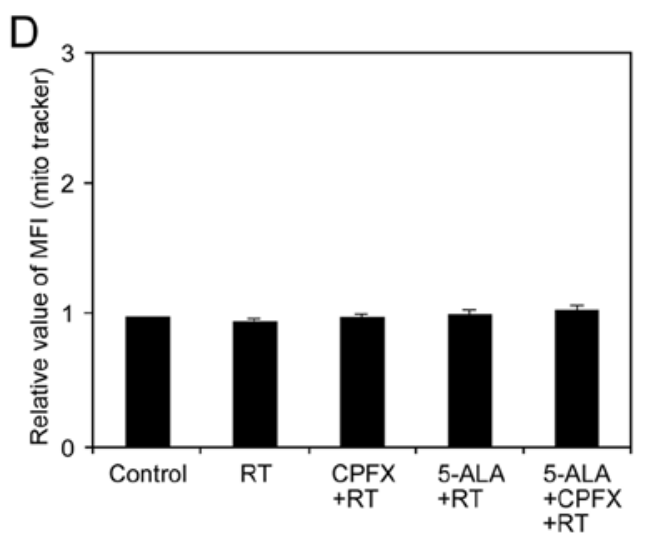

F

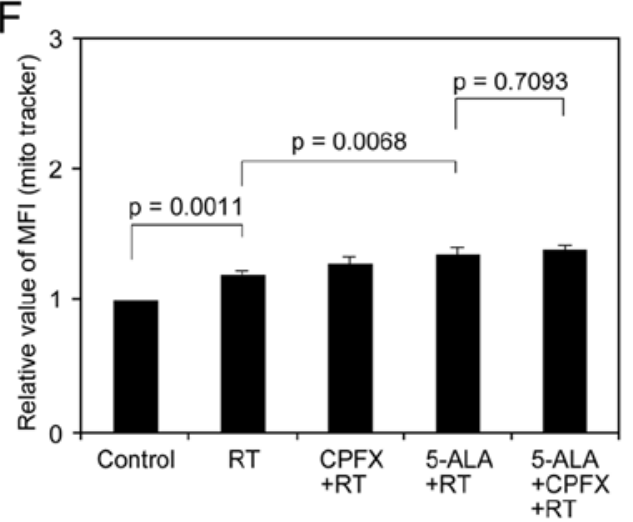

Figure 5. Mitochondrial mass in glioma cells after ionizing irradiation exposure. Mitochondrial mass was measured by Mito Tracker Green FM staining using flow cytometric analyses just after (A, C and D) and $12 \mathrm{~h}$ after ionizing irradiation exposure (B, E and F). Control cells were not treated with 5-aminolevulinic acid (5-ALA) or ciprofloxacin (CPFX) and not exposed to ionizing irradiation. Representative flow cytometric profiles of mitochondrial mass levels in 9L cells just after (A), and $12 \mathrm{~h}$ after ionizing irradiation exposure (B). Relative median fluorescence intensity (MFI) of Mito Tracker Green FM without ionizing irradiation compared with the control in 9L (C and D) and U251 cells (D and F). RT, cells exposed to only ionizing irradiation without CPFX and 5-ALA; $\mathrm{CPFX}+\mathrm{RT}$, cells pretreated with CPFX and exposed to ionizing irradiation; 5-ALA+RT, cells pretreated with 5-ALA and exposed to ionizing irradiation; $5-\mathrm{ALA}+\mathrm{CPFX}+\mathrm{RT}$, cells pretreated with 5-ALA and exposed to ionizing irradiation. Values indicate mean $\pm \mathrm{SE}(\mathrm{n}=6)$.

Differences in amount of 5-ALA-induced PpIX accumulation influence mitochondrial mass after IR in glioma cells. To evaluate the influence of different amounts of 5-ALA-induced PpIX accumulation on mitochondrial mass after IR, we evaluated mitochondrial mass after IR in glioma cells treated with low-dose CPFX using flow cytometric analysis. The mitochondrial mass of glioma cells was obviously changed between just after and $12 \mathrm{~h}$ after IR exposure (Fig. 5A and B). In both glioma cell lines just after IR, the differences among treatment groups were not marked (Fig. 5C and D). In the 9L and U251 cells $12 \mathrm{~h}$ after IR, the relative MFI of mitochondria in cells with RT was $1.36 \pm 0.02$ and $1.20 \pm 0.04$, respectively (Fig. 5E and F), significant increases compared to the control $(\mathrm{p}<0.0001$ and $\mathrm{p}=0.0011$, respectively). The cells receiving $\mathrm{RT}$ with 5-ALA treatment also exhibited significantly increased mitochondrial mass compared to the cells receiving RT in the two cell lines $(1.42 \pm 0.02, \mathrm{p}=0.0453$ in $9 \mathrm{~L} ; 1.36 \pm 0.05, \mathrm{p}=0.0068$ in $\mathrm{U} 251)$. Although the cells receiving RT with 5-ALA and CPFX treatment exhibited increased mitochondrial mass compared to the cells receiving RT with 5-ALA treatment in the two cell lines $(1.44 \pm 0.03$ in $9 \mathrm{~L}, 1.38 \pm 0.04$ in $\mathrm{U} 251)$, the differences were not significant ( $\mathrm{p}=0.3240$ and 0.7093 , respectively).

IR with 5-ALA treatment increases mitochondrial complex III activity in glioma cells. Since delayed ROS production in tumour cells after IR was associated with mitochondrial ETC activity (24-27) we evaluated mitochondrial ETC activity using Total OXPHOS Rodent WB Antibody Cocktail $(32,33)$. In glioma cells before IR, the relative complex III value in CPFX, 5-ALA, and 5-ALA with CPFX treatment groups was $1.02 \pm 0.09,1.61 \pm 0.13$ and $1.75 \pm 0.26$, respectively, in $9 \mathrm{~L}$ cells and $1.14 \pm 0.02,1.23 \pm 0.13$ and $1.44 \pm 0.28$, respectively, in U251 cells (Fig. 6A and B). 5-ALA treatment increased complex III activity in glioma cells with some variations ( $p=0.0463$ in $9 \mathrm{~L}, \mathrm{p}=0.4203$ in U251). Complex III activity in glioma cells $12 \mathrm{~h}$ after RT in each group increased compared to that just after RT (Fig. 6C-G). In glioma cells just after IR, the relative complex III value in the RT, CPFX, 5-ALA, and 5-ALA with CPFX treatment groups was $1.18 \pm 0.16$, $1.24 \pm 0.15,2.13 \pm 0.13$ and $2.33 \pm 0.40$, respectively, in $9 \mathrm{~L}$ cells and $1.22 \pm 0.13,1.37 \pm 0.23,1.44 \pm 0.30$ and $1.74 \pm 0.39$, respectively, in U251 cells (Fig. 6C and D). Complex III activity in 9L cells receiving 5-ALA treatment just after RT obviously increased compared to those receiving only RT $(\mathrm{p}=0.0286)$. In glioma cells $12 \mathrm{~h}$ after IR, the relative complex III value in RT, CPFX, 5-ALA, and 5-ALA with CPFX treatment groups was $2.07 \pm 0.07,2.38 \pm 0.31,3.06 \pm 0.04$ and $4.02 \pm 0.42$, respectively, in $9 \mathrm{~L}$ cells and $1.40 \pm 0.14,2.08 \pm 0.31,3.05 \pm 0.18$ and $3.28 \pm 0.34$, respectively, in $\mathrm{U} 251$ cells (Fig. $6 \mathrm{E}$ and F). At $12 \mathrm{~h}$ after RT, complex III activity in the RT group increased compared to 

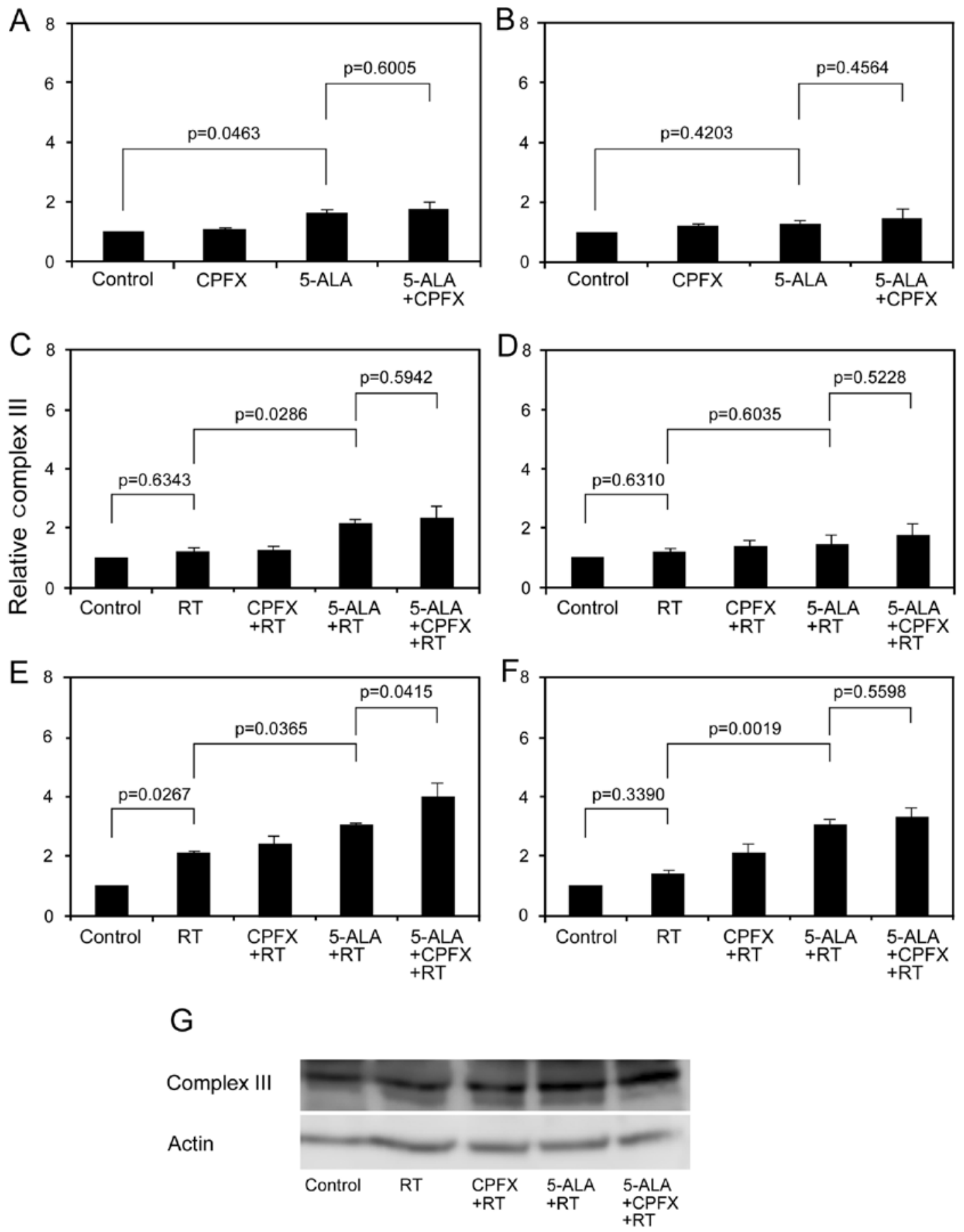

Figure 6. Expression of mitochondrial complex III after ionizing irradiation exposure in glioma cells. Cell lysates were collected (A and B) before, (C and D) just after, and (E and F) $12 \mathrm{~h}$ after ionizing irradiation exposure and then analysed by western blotting using Total OXPHOS Rodent WB Antibody Cocktail. Control cells were not treated with 5-aminolevulinic acid (5-ALA) or ciprofloxacin (CPFX) and not exposed to ionizing irradiation. The level of complex III was normalized to actin and then compared to that of the control in (A, C and E) 9L cells and (B, D and F) U251 cells. (G) Representative gels of complex III expression $12 \mathrm{~h}$ after ionizing irradiation exposure in $9 \mathrm{~L}$ cells. Values indicate mean $\pm \mathrm{SE}(\mathrm{n}=3)$.

control in 9L and U251 cells with some variations ( $\mathrm{p}=0.0267$ in $9 \mathrm{~L}, \mathrm{p}=0.3390$ in U251). However, complex III activity in the RT with 5-ALA treatment group significantly increased compared to that in the RT group in the two cell lines ( $p=0.0365$ in $9 \mathrm{~L}, \mathrm{p}=0.0019$ in U251). Complex III activity for RT with 5-ALA and CPFX treatment increased compared to that for RT with 5-ALA treatment in 9L cells $(\mathrm{p}=0.0415)$ and $\mathrm{U} 251$ cells $(\mathrm{p}=0.5598)$ (Fig. 6E-G). Although we similarly evaluated other mitochondrial complexes (I, II, IV and V), there were no apparent differences (data not shown).

\section{Discussion}

5-ALA enhances mitochondrial stress by IR and leads to increased cell death with mitochondrial changes in glioma cells. We previously demonstrated that 5-ALA enhances the delayed production of ROS after IR mainly in the cytoplasm, supposed as the mitochondria, of glioma cells $(14,15,24)$. In the present study, to elucidate the radiosensitizing effect of 5-ALA in glioma cells, we investigated the cell response after IR with different amounts of 5-ALA-induced PpIX accumulation in 
glioma cells, focusing on mitochondria. We confirmed that the enhancement of delayed ROS production and cell death via IR was proportionate to 5-ALA-induced PpIX accumulation in glioma cells and that delayed ROS production occurred within the increased mitochondria of glioma cells. Moreover, IR with 5-ALA treatment increased the mitochondrial mass and mitochondrial complex III activity at $12 \mathrm{~h}$ after irradiation, leading to cell death proportionate to 5-ALA-induced PpIX accumulation in glioma cells. To the best of our knowledge, this is the first study to investigate the radiosensitizing effect of 5-ALA with a focus on the response of mitochondria in glioma cells.

Most anticancer drugs induce targeted cell death, at least in part, through the generation of elevated amounts of intracellular ROS (34). Thus, non-toxic materials that selectively upregulate intracellular ROS to induce lethal effects for tumour cells are desirable. In general, the biological consequences of IR leading to cell death are highly influenced by the activation of the DNA damage response mechanism, particularly for nuclear DSBs $(35,36)$. However, the number of studies investigating the effects of IR on the mitochondria is far less than that on the cell nucleus (25). Mitochondria occupy a fairly substantial fraction of cell volume (4-25\% depending on the cell), which renders them a likely target of radiation traversal through the cell (37). Mitochondrial DNA only accounts for approximately $0.25 \%$ of the total cellular DNA, but all of the mitochondrial DNA (except the D-loop) consists of genes for protein synthesis $(38,39)$. In addition, mitochondrial DNA is considered more prone to oxidative damage because it lacks histone protection and an efficient DNA repair system $(40,41)$. Thus, recent studies suggest that mitochondria are specific targets in the tumouricidal efficacy of radiation therapy (25-27).

The increase in delayed ROS production and mitochondrial mass was hypothesized to arise from the propagation of oxidative stress from impaired mitochondria initially damaged by IR, so-called 'amplification of intermitochondrial communication' (25). In the present study, we confirmed that IR without 5-ALA treatment increased delayed ROS production and mitochondrial mass at the late period in glioma cells, consistent with previous studies $(24,28)$. However, 5-ALA-induced PpIX accumulation obviously enhanced delayed ROS production and mitochondrial mass in glioma cells. Additionally, the enhancement of these delayed ROS production obviously occurred in the 'mitochondria' and not in the 'nucleus'. Considering the characteristics of ROS (very short lifetime and limited diffusion distance) and the distance between impaired mitochondria, surrounding normal mitochondria, and the nucleus, renders this distribution of delayed ROS production reasonable (21). Thus, the direct biological effects of delayed ROS on the nucleus may be limited, at least in the late period after IR with 5-ALA treatment.

The precise mechanism by which 5-ALA-induced PpIX enhances delayed ROS production remains unclear. Mitochondria play important roles in ROS production during IR exposure (27). In addition, mitochondria consume approximately $90 \%$ of physiological oxygen and are the richest source of ROS $(42,43)$. In the present study, we observed that 5-ALA-induced PpIX enhanced complex III activity $12 \mathrm{~h}$ after IR in glioma cells. Thus, during amplification of intermitochondrial communication at the late period after IR with 5-ALA treatment, electron leakage may occur in the ETC complex of mitochondria damaged by oxidative stress, consequently elevating delayed ROS production $(25,27)$. PpIX enhances ROS production in solution via water radiolysis induced by IR (23). We also observed that 5-ALA-induced PpIX increased primary ROS production by IR and localized with these ROS in glioma cells (14). By contrast, although glioma cells were treated with 5-ALA after IR, delayed ROS production was not so elevated in our previous study (16). Taken together, for cells that accumulate large amounts of 5-ALA-induced PpIX in mitochondria, IR can initially induce strong oxidative stress to mitochondria and subsequently enhance delayed ROS production by amplifying intermitochondrial communication, consequently inducing strong cell death in glioma cells. Thus, we suggest that 5-ALA enhances the mitochondrial stress induced by IR, thereby acting as a radiosensitizer in gliomas.

Low-dose CPFX enhances 5-ALA radiosensitization effects by increasing PpIX accumulation in glioma cells. CPFX is known to enhance 5-ALA-induced PpIX in tumour cells, and a previous study demonstrated that $100 \mu \mathrm{M}$ CPFX enhanced 5-ALA-induced PpIX accumulation in human epithelial cervical cancer (HeLa) and epidermoid carcinoma (A431) cells (31). CPFX also has anticancer effects in several tumour cell lines with some variations (44). Therefore, we first evaluated the cytotoxicity of CPFX for glioma cells and chose $5 \mu \mathrm{M}$ as the appropriate concentration of CPFX for glioma cells (Fig. 1). Despite the low dose, CPFX increased 5-ALA-induced PpIX accumulation without its own cytotoxicity and enhanced cell death by IR in glioma cells. Recent studies demonstrated that the accumulation of 5-ALA-induced PpIX in tumour cells varies depending on the tumour cell types and local cellular environment via four possible processes: i) enzyme activity of heme synthesis (45), ii) membrane transporters (influx of 5-ALA, efflux of PpIX) (46-48), iii) iron metabolism $(49,50)$ and iv) turnover rate of heme synthesis (51). In the final step of heme synthesis in mitochondria, iron $\left(\mathrm{Fe}^{2+}\right)$ is inserted into PpIX by ferrochelatase to form heme (7). CPFX acts as an iron-chelator, decreasing iron utilization for heme biosynthesis in the mitochondria of tumour cells, consequently leading to elevated 5-ALA-induced PpIX accumulation (31). In addition, CPFX itself acts as a radiosensitizer in tumour cells (30). CPFX promotes p53 phosphorylation (cell-cycle arrest), reduces Bcl-2 production (anti-apoptotic effect), and leads to increased cell death in tumour cells (30). Our results also confirm the radiosensitizing effect of CPFX in glioma cells, although it was weak compared to that of 5-ALA. Although the biological effect of CPFX on mitochondria, such as increasing mitochondrial mass and mitochondrial complex activity, was decreased, CPFX treatment delayed ROS production after IR in glioma cells with some variations. Thus, CPFX itself may affect the nucleus and enhance delayed ROS production in cellular organelles except for the mitochondria.

5-ALA as a candidate drug for direct mitochondrial targeting in cancer therapy using IR. In the past, cancer drugs mainly targeted specific molecular signals associated with cell proliferation, cell death, cellular differentiation, and tumour angiogenesis (52-55). However, these molecular pathways are multifaceted, and an alternative anticancer strategy targeting 
tumour metabolism is required (56). Mitochondria are the centre arena of cell metabolism, such as ATP production, lethal signal transduction, and intracellular ROS production. Thus, emerging studies have begun to investigate mitochondrial metabolism as a specific target for cancer therapy $(57,58)$. 5-ALA can certainly accumulate PpIX in the mitochondria of tumour cells $(6,7)$. In addition, 5-ALA is already used in clinical applications, such as fluorescence-guided resection for malignant gliomas, without adverse effects (8-10). In the present study, we demonstrated that 5-ALA obviously enhanced delayed ROS production within mitochondria, leading to enhanced mitochondrial changes induced by IR. Importantly, these processes occur in the specific mitochondrial arena. Thus, we suggest that 5-ALA has potential as a drug for the direct targeting of mitochondria in cancer therapy under IR exposure.

The radiosensitizing effects of porphyrin compounds such as Photofrin and HpD have been reported (59-61). A recent study demonstrated the use of radiotherapy with tumour-specific folic acid-conjugated carboxymethyl lauryl chitosan/superparamagnetic iron oxide micelles to effectively deliver porphyrin compounds (chlorin e6) to cancer cells (62). Although 5-ALA is well-known as a specific reagent for photodynamic therapy and fluorescence-guided resection in neurosurgery $(8,63), 5$-ALA is not itself a porphyrin compound but a prodrug that is converted into PpIX within tumour cell mitochondria (7). For radiotherapy combined with 5-ALA, we consider that it is important to increase the PpIX concentration within tumour cells, specifically in mitochondria, just before IR exposure. We previously confirmed that cell death by single-dose IR with 5-ALA treatment was weak, but multi-dose IR with repeated 5-ALA treatment enhanced cell death in experimental glioma $(14,15)$. Previous findings demonstrated that IR decreases the activity of mitochondrial aconitase and iron regulatory protein-1, which are essential for the function of iron-sulphur clusters in mitochondria (26). Thus, IR may insult utilization of iron on heme synthesis at mitochondria and consequently enhance 5-ALA-induced PpIX accumulation within mitochondria. Tumour cells after IR exposure exhibit increased 5-ALA-induced PpIX accumulation $(12,16)$. For multi-dose (fractionated) IR, the PpIX concentration within tumour cells may be altered with each fraction. In addition, we previously confirmed 5-ALA-induced PpIX as a potential biomarker for malignant gliomas via MRI in a prospective clinical case study (64). Therefore, we suggest that modulation of the intensity and field of the radiation beam based on 5-ALA-induced PpIX tumour concentrations evaluated by MRI for each patient and for each fraction can increase the therapeutic effect in tumours and decrease the side effects of IR, such as radiation necrosis, brain oedema, and leukoencephalopathy, on normal surrounding tissue by avoiding excessive IR exposure. Further investigation into the biological effects of IR on glioma cells based on the 5-ALA-induced PpIX concentration is required.

Interactions between 5-ALA and ultrasound, so-called sonodynamic therapy, and hyperthermia have been previously reported as cancer therapy $(65,66)$. These external energy exposures may affect mitochondrial accumulation of 5-ALA-induced PpIX and revealed that the antitumour effect is the same as that of IR. Since their introduction in the late 1990s, cancer stem cells (CSCs) have been shown to be more radioresistant/chemoresistant than non-stem cells via enhanced DNA-repair capacity, ROS defences, and self-renewal potential (67-69). Although mitochondria are the most prominent source of intracellular ROS, low levels of ROS have been involved in cancer cell stemness (70). However, a recent study demonstrated that photodynamic therapy (PDT) using 5-ALA reduced the self-renewal property and stemness signature expression in CSCs (71). In addition, PDT with 5-ALA enhanced the sensitivity of CSCs to chemotherapy (cisplatin) by suppressing ABCG2 (the efflux transporter of PpIX) and led to reduced tumourigenicity of CSCs. Thus, CSCs may accumulate 5-ALA-induced PpIX within mitochondria such as non-progenitor tumour cells. If this occurs, radiotherapy with 5-ALA constitutes an effective cancer treatment for CSCs. Therefore, it is crucial to investigate how to combine existing therapy with 5-ALA and to extend the application of 5-ALA, so called 'drug repositioning', in future studies.

In conclusion, 5-ALA is a useful tool for fluorescenceguided resection in malignant gliomas as a live molecular marker. Furthermore, 5-ALA selectively accumulates PpIX in mitochondria and induces strong oxidative stress in glioma cell mitochondria under IR. Thus, 5-ALA shows potential as a mitochondria-targeting drug in cancer therapy.

\section{Acknowledgements}

We appreciate Dr Hitoshi Nakagawa and Dr Masahiro Ishizuka (SBI Pharmaceuticals Co., Ltd., Minato-ku, Tokyo, Japan) for advice regarding western blotting for OXPHOS. This study was supported by JSPS KAKENHI (grant no. 25462282).

\section{References}

1. Sanai N, Polley MY, McDermott MW, Parsa AT and Berger MS: An extent of resection threshold for newly diagnosed glioblastomas. J Neurosurg 115: 3-8, 2011.

2. Stupp R, Mason WP, van den Bent MJ, Weller M, Fisher B, Taphoorn MJ, Belanger K, Brandes AA, Marosi C, Bogdahn U, et al; European Organisation for Research and Treatment of Cancer Brain Tumor and Radiotherapy Groups; National Cancer Institute of Canada Clinical Trials Group: Radiotherapy plus concomitant and adjuvant temozolomide for glioblastoma. N Engl J Med 352: 987-996, 2005.

3. Westphal M, Ram Z, Riddle V, Hilt D and Bortey E; Executive Committee of the Gliadel Study Group: Gliadel wafer in initial surgery for malignant glioma: Long-term follow-up of a multicenter controlled trial. Acta Neurochir (Wien) 148: 269-275, 2006.

4. Claes A, Idema AJ and Wesseling P: Diffuse glioma growth: A guerilla war. Acta Neuropathol 114: 443-458, 2007.

5. Minniti G, Amelio D, Amichetti M, Salvati M, Muni R, Bozzao A, Lanzetta G, Scarpino S, Arcella A and Enrici RM: Patterns of failure and comparison of different target volume delineations in patients with glioblastoma treated with conformal radiotherapy plus concomitant and adjuvant temozolomide. Radiother Oncol 97: 377-381, 2010.

6. Ishizuka M, Abe F, Sano Y, Takahashi K, Inoue K, Nakajima M, Kohda T, Komatsu N, Ogura S and Tanaka T: Novel development of 5-aminolevurinic acid (ALA) in cancer diagnoses and therapy. Int Immunopharmacol 11: 358-365, 2011.

7. Yamamoto J: A role of 5-aminolevulinic acid for treating malignant gliomas: Clinical implications and future prospects (Review). ALA-Porphyrin Sci 4: 3-12, 2016.

8. Stummer W, Pichlmeier U, Meinel T, Wiestler OD, Zanella F and Reulen HJ; ALA-Glioma Study Group: Fluorescence-guided surgery with 5-aminolevulinic acid for resection of malignant glioma: A randomised controlled multicentre phase III trial. Lancet Oncol 7: 392-401, 2006. 
9. Yamamoto J, Kitagawa T, Akiba D and Nishizawa S: 5-Aminolevulinic acid-induced fluorescence in cerebellar primary central nervous system lymphoma: A case report and literature review. Turk Neurosurg 25: 796-800, 2015.

10. Yamamoto J, Takahashi M, Idei M, et al: A pitfall of fluorescenceguided surgery with 5-aminolevulinic acid for the treatment of malignant brain tumor-case report-. ALA-Porphyrin Sci 1: 61-66, 2012.

11. Luksiene Z, Berg K and Moan J: Combination of photodynamic therapy and X-irradiation: A study on 5-ALA radiomodifying properties. SPIE 2325: 306-311, 1994.

12. Berg K, Luksiene Z, Moan J and Ma L: Combined treatment of ionizing radiation and photosensitization by 5 -aminolevulinic acid-induced protoporphyrin IX. Radiat Res 142: 340-346, 1995.

13. Schaffer M, Schaffer PM, Corti L, Gardiman M, Sotti G Hofstetter A, Jori G and Dühmke E: Photofrin as a specific radiosensitizing agent for tumors: Studies in comparison to other porphyrins, in an experimental in vivo model. J Photochem Photobiol B 66: 157-164, 2002

14. Yamamoto J, Ogura S, Tanaka T, Kitagawa T, Nakano Y, Saito T, Takahashi M, Akiba D and Nishizawa S: Radiosensitizing effect of 5-aminolevulinic acid-induced protoporphyrin IX in glioma cells in vitro. Oncol Rep 27: 1748-1752, 2012.

15. Yamamoto J, Ogura S, Shimajiri S, Nakano Y, Akiba D, Kitagawa T, Ueta K, Tanaka T and Nishizawa S: 5-Aminolevulinic acid-induced protoporphyrin IX with multi-dose ionizing irradiation enhances host antitumor response and strongly inhibits tumor growth in experimental glioma in vivo. Mol Med Rep 11: $1813-1819,2015$.

16. Kitagawa T, Yamamoto J, Tanaka T, Nakano Y, Akiba D, Ueta K and Nishizawa S: 5-Aminolevulinic acid strongly enhances delayed intracellular production of reactive oxygen species (ROS) generated by ionizing irradiation: Quantitative analyses and visualization of intracellular ROS production in glioma cells in vitro. Oncol Rep 33: 583-590, 2015.

17. Takahashi J, Misawa M, Murakami M, Mori T, Nomura K and Iwahashi H: 5-Aminolevulinic acid enhances cancer radiotherapy in a mouse tumor model. Springerplus 2: 602, 2013.

18. Kamada Y, Murayama Y, Harada K, Nishimura M, Kondo Y, Konishi H, Morimura R, Komatsu S, Shiozaki A, Kuriu Y, et al: Radiosensitizing effect of 5-aminolevulinic acid (5-ALA) in Colon cancer. Gan To Kagaku Ryoho 41: 1608-1610, 2014 (In Japanese).

19. Wang D, Cvetkovic B, Gupta R, Chen L, Ma CMC, Zhang Q and Zeng J: Radiatoin therapy combined with 5-amiolevulinic acid: A preliminary study with an in vivo mouse model implanted with human PC-3 tumor cells. Int J Radiat Oncol Biol Phys 93: e522, 2015.

20. Takahashi J, Misawa M and Iwahashi $\mathrm{H}$ : Transcriptome analysis of porphyrin-accumulated and x-ray-irradiated cell cultures under limited proliferation and non-lethal conditions. Microarrays (Basel) 4: 25-40, 2015.

21. Riley PA: Free radicals in biology: Oxidative stress and the effects of ionizing radiation. Int J Radiat Biol 65: 27-33, 1994.

22. Hall E and Giaccia A (eds): Physics and chemistry of radiation absorption. In: Radiology for the Radiologist. Lippipncott Williams and Wilkins, Philadelphia, PA, pp5-15, 2006.

23. Takahashi $\mathbf{J}$ and Misawa $\mathbf{M}$ : Characterization of reactive oxygen species generated by protoporphyrin IX under X-ray irradiation. Radiat Phys Chem 78: 889-898, 2009.

24. Yamamori T, Yasui H, Yamazumi M, Wada Y, Nakamura Y, Nakamura $\mathrm{H}$ and Inanami O: Ionizing radiation induces mitochondrial reactive oxygen species production accompanied by upregulation of mitochondrial electron transport chain function and mitochondrial content under control of the cell cycle checkpoint. Free Radic Biol Med 53: 260-270, 2012.

25. Kam WW and Banati RB: Effects of ionizing radiation on mitochondria. Free Radic Biol Med 65: 607-619, 2013

26. Azzam EI, Jay-Gerin JP and Pain D: Ionizing radiation-induced metabolic oxidative stress and prolonged cell injury. Cancer Lett 327: 48-60, 2012.

27. Richardson RB and Harper ME: Mitochondrial stress controls the radiosensitivity of the oxygen effect: Implications for radiotherapy. Oncotarget: Feb 15, 2016 (Epub ahead of print).

28. Saenko Y, Cieslar-Pobuda A, Skonieczna M and RzeszowskaWolny J: Changes of reactive oxygen and nitrogen species and mitochondrial functioning in human K562 and HL60 cells exposed to ionizing radiation. Radiat Res 180: 360-366, 2013.

29. Sugiyama Y, Hagiya Y, Nakajima M, Ishizuka M, Tanaka T and Ogura S: The heme precursor 5-aminolevulinic acid disrupts the Warburg effect in tumor cells and induces caspase-dependent apoptosis. Oncol Rep 31: 1282-1286, 2014.
30. Kiang JG, Garrison BR, Smith JT and Fukumoto R: Ciprofloxacin as a potential radio-sensitizer to tumor cells and a radio-protectant for normal cells: Differential effects on $\gamma$-H2AX formation, p53 phosphorylation, Bcl-2 production, and cell death. Mol Cell Biochem 393: 133-143, 2014.

31. Ohgari Y, Miyata Y, Chau TT, Kitajima S, Adachi Y and Taketani S: Quinolone compounds enhance delta-aminolevulinic acid-induced accumulation of protoporphyrin IX and photosensitivity of tumour cells. J Biochem 149: 153-160, 2011.

32. Kanzleiter T, Rath M, Penkov D, Puchkov D, Schulz N, Blasi F and Schürmann A: Pknox1/Prep1 regulates mitochondrial oxidative phosphorylation components in skeletal muscle. Mol Cell Biol 34: 290-298, 2014.

33. Thomas MM, Trajcevski KE, Coleman SK, Jiang M, Di Michele J, O'Neill HM, Lally JS, Steinberg GR and Hawke TJ: Early oxidative shifts in mouse skeletal muscle morphology with high-fat diet consumption do not lead to functional improvements. Physiol Rep 2: 2, 2014.

34. Wondrak GT: Redox-directed cancer therapeutics: Molecular mechanisms and opportunities. Antioxid Redox Signal 11: 3013-3069, 2009

35. Lomax ME, Folkes LK and O'Neill P: Biological consequences of radiation-induced DNA damage: Relevance to radiotherapy. Clin Oncol (R Coll Radiol) 25: 578-585, 2013.

36. Barendsen GW: The relationships between RBE and LET for different types of lethal damage in mammalian cells: Biophysical and molecular mechanisms. Radiat Res 139: 257-270, 1994.

37. Leach JK, Van Tuyle G, Lin PS, Schmidt-Ullrich R and Mikkelsen RB: Ionizing radiation-induced, mitochondriadependent generation of reactive oxygen/nitrogen. Cancer Res 61: 3894-3901, 2001.

38. Clayton DA: Transcription and replication of mitochondrial DNA. Hum Reprod 15 (Suppl 2): 11-17, 2000.

39. Anderson S, Bankier AT, Barrell BG, de Bruijn MH, Coulson AR, Drouin J, Eperon IC, Nierlich DP, Roe BA, Sanger F, et al: Sequence and organization of the human mitochondrial genome. Nature 290: 457-465, 1981

40. Richter C, Park JW and Ames BN: Normal oxidative damage to mitochondrial and nuclear DNA is extensive. Proc Natl Acad Sci USA 85: 6465-6467, 1988.

41. Larsen NB, Rasmussen M and Rasmussen LJ: Nuclear and mitochondrial DNA repair: Similar pathways? Mitochondrion 5: 89-108, 2005

42. Cadenas E and Davies KJ: Mitochondrial free radical generation, oxidative stress, and aging. Free Radic Biol Med 29: 222-230, 2000.

43. Babior BM: NADPH oxidase: An update. Blood 93: 1464-1476, 1999.

44. Kloskowski T, Gurtowska N, Nowak M, Joachimiak R, Bajek A, Olkowska $J$ and Drewa T: The influence of ciprofloxacin on viability of A549, HepG2, A375.S2, B16 and C6 cell lines in vitro. Acta Pol Pharm 68: 859-865, 2011.

45. Teng L, Nakada M, Zhao SG, Endo Y, Furuyama N, Nambu E, Pyko IV, Hayashi Y and Hamada JI: Silencing of ferrochelatase enhances 5-aminolevulinic acid-based fluorescence and photodynamic therapy efficacy. Br J Cancer 104: 798-807, 2011.

46. Tran TT, Mu A, Adachi Y, Adachi Y and Taketani S: Neurotransmitter transporter family including SLC6A6 and SLC6A13 contributes to the 5-aminolevulinic acid (ALA)induced accumulation of protoporphyrin IX and photodamage, through uptake of ALA by cancerous cells. Photochem Photobiol 90: 1136-1143, 2014

47. Chua C, Zaiden N, Chong KH, See SJ, Wong MC, Ang BT and Tang C: Characterization of a side population of astrocytoma cells in response to temozolomide. J Neurosurg 109: 856-866, 2008.

48. Matsumoto K, Hagiya Y, Endo Y, Nakajima M, Ishizuka M, Tanaka T and Ogura S: Effects of plasma membrane ABCB6 on 5-aminolevulinic acid (ALA)-induced porphyrin accumulation in vitro: Tumor cell response to hypoxia. Photodiagn Photodyn Ther 12: 45-51, 2015.

49. Hayashi M, Fukuhara H, Inoue K, Shuin T, Hagiya Y, Nakajima M, Tanaka T and Ogura S: The effect of iron ion on the specificity of photodynamic therapy with 5-aminolevulinic acid. PLoS One 10: e0122351, 2015.

50. Sawamoto M, Imai T, Umeda M, Fukuda K, Kataoka T and Taketani S: The p53-dependent expression of frataxin controls 5-aminolevulinic acid-induced accumulation of protoporphyrin IX and photo-damage in cancerous cells. Photochem Photobiol 89: 163-172, 2013. 
51. Kim JE, Cho HR, Xu WJ, Kim JY, Kim SK, Kim SK, Park SH Kim H, Lee SH, Choi SH, et al: Mechanism for enhanced 5-aminolevulinic acid fluorescence in isocitrate dehydrogenase 1 mutant malignant gliomas. Oncotarget 6: 20266-20277, 2015.

52. Uhm JH, Ballman KV, Wu W, Giannini C, Krauss JC, Buckner JC, James CD, Scheithauer BW, Behrens RJ, Flynn PJ, et al: Phase II evaluation of gefitinib in patients with newly diagnosed Grade 4 astrocytoma: Mayo/North Central Cancer Treatment Group Study N0074. Int J Radiat Oncol Biol Phys 80: 347-353, 2011.

53. Curry WT and Lim M: Immunomodulation: checkpoint blockade etc. Neuro Oncol 17 (Suppl 7): vii26-vii31, 2015.

54. Norden AD, Drappatz J and Wen PY: Novel anti-angiogenic therapies for malignant gliomas. Lancet Neurol 7: 1152-1160, 2008.

55. CloughesyT, Finocchiaro G, Belda-Iniesta C, Recht L, Brandes AA, Pineda E, Mikkelsen T, Chinot OL, Balana C, Macdonald DR, et al: Randomized, double-blind, placebo-controlled, multicenter phase II study of onartuzumab plus bevacizumab versus placebo plus bevacizumab in patients with recurrent glioblastoma: efficacy, safety, and hepatocyte growth factor and O6-methylguanine-DNA methyltransferase biomarker analyses. J Clin Oncol Dec 5, 2016 (Epub ahead of print)

56. Pan JG and Mak TW: Metabolic targeting as an anticancer strategy: Dawn of a new era? Sci STKE 2007: pe14, 2007.

57. Fulda S, Galluzzi L and Kroemer G: Targeting mitochondria for cancer therapy. Nat Rev Drug Discov 9: 447-464, 2010.

58. Weinberg SE and Chandel NS: Targeting mitochondria metabolism for cancer therapy. Nat Chem Biol 11: 9-15, 2015.

59. Kostron H, Swartz MR, Miller DC and Martuza RL: The interaction of hematoporphyrin derivative, light, and ionizing radiation in a rat glioma model. Cancer 57: 964-970, 1986.

60. Kulka U, Schaffer M, Siefert A, Schaffer PM, Olsner A, Kasseb K, Hofstetter A, Dühmke E and Jori G: Photofrin as a radiosensitizer in an in vitro cell survival assay. Biochem Biophys Res Commun 311: 98-103, 2003.

61. Schaffer M, Ertl-Wagner B, Schaffer PM, Kulka U, Jori G, Wilkowski R, Hofstetter A and Dühmke E: Feasibility of photofrin II as a radiosensitizing agent in solid tumors preliminary results. Onkologie 29: 514-519, 2006.
62. Chen HP, Tung FI, Chen MH and Liu TY: A magnetic vehicle realized tumor cell-targeted radiotherapy using low-dose radiation. J Control Release 226: 182-192, 2016.

63. Yamamoto J, Yamamoto S, Hirano T, Li S, Koide M, Kohno E, Okada M, Inenaga C, Tokuyama T, Yokota N, et al: Monitoring of singlet oxygen is useful for predicting the photodynamic effects in the treatment for experimental glioma. Clin Cancer Res 12: 7132-7139, 2006.

64. Yamamoto J, Kakeda S, Yoneda T, et al: Improving contrast enhancement in magnetic resonance imaging using 5-aminolevulinic acid-induced protoporphyrin IX for high-grade gliomas: A prospective case study and clinical implications. Oncol Lett (In press).

65. Gao Z, Zheng J, Yang B, Wang Z, Fan H, Lv Y, Li H, Jia L and Cao W: Sonodynamic therapy inhibits angiogenesis and tumor growth in a xenograft mouse model. Cancer Lett 335: 93-99, 2013.

66. Takahashi K, Hasegawa T, Ishii T, Suzuki A, Nakajima M, Uno K, Yasuda I, Kishi A, Sadamoto K, Abe F, et al: Antitumor effect of combination of hyperthermotherapy and 5-aminolevulinic acid (ALA). Anticancer Res 33: 2861-2866, 2013.

67. Rycaj K and Tang DG: Cancer stem cells and radioresistance. Int J Radiat Biol 90: 615-621, 2014.

68. Krause M, Dubrovska A, Linge A and Baumann M: Cancer stem cells: Radioresistance, prediction of radiotherapy outcome and specific targets for combined treatments. Adv Drug Deliv Rev: Feb 12, 2016 (Epub ahead of print).

69. Tannock IF: Cancer: Resistance through repopulation. Nature 517: 152-153, 2015

70. Diehn M, Cho RW, Lobo NA, Kalisky T, Dorie MJ, Kulp AN, Qian D, Lam JS, Ailles LE, Wong M, et al: Association of reactive oxygen species levels and radioresistance in cancer stem cells. Nature 458: 780-783, 2009.

71. Yu CH and Yu CC: Photodynamic therapy with 5-aminolevulinic acid (ALA) impairs tumor initiating and chemo-resistance property in head and neck cancer-derived cancer stem cells. PLoS One 9: e87129, 2014. 